Article

\title{
In Situ Generated Nanosized Sulfide Ni-W Catalysts Based on Zeolite for the Hydrocracking of the Pyrolysis Fuel Oil into the BTX Fraction
}

\author{
Tatiana Kuchinskaya *, Mariia Kniazeva $₫$, Vadim Samoilov $₫$ and Anton Maximov \\ A.V. Topchiev Institute of Petrochemical Synthesis, Russian Academy of Sciences (TIPS RAS), 119991 Moscow, \\ Russia; knyazeva@ips.ac.ru (M.K.); samoilov@ips.ac.ru (V.S.); max@ips.ac.ru (A.M.) \\ * Correspondence: kuchinskaya@ips.ac.ru; Tel.: +7-495-647-5927 (ext. 349)
}

Received: 9 September 2020; Accepted: 1 October 2020; Published: 7 October 2020

check for updates

\begin{abstract}
The hydrocracking reaction of a pyrolysis fuel oil fraction using in situ generated nano-sized NiWS-sulfide catalysts is studied. The obtained catalysts were defined using X-ray photoelectron spectroscopy (XPS) and transmission electron microscopy (TEM). The features of catalytically active phase generation, as well as its structure and morphology were considered. The catalytic reactivity of in situ generated catalysts was evaluated using the hydrocracking reaction of pyrolysis fuel oil to obtain a light fraction to be used as a feedstock for benzene, toluene, and xylene (BTX) production. It was demonstrated that the temperature of $380^{\circ} \mathrm{C}$, pressure of $5 \mathrm{MPa}$, and catalyst-to-feedstock ratio of $4 \%$ provide for a target fraction (IPB $-180{ }^{\circ} \mathrm{C}$ ) yield of $44 \mathrm{wt} \%$, and the BTX yield of reaching $15 \mathrm{wt} \%$.
\end{abstract}

Keywords: BTX; dispersed catalysts; hydroconversion; pyrolysis fuel oil; zeolites; in situ formed catalysts; nanocatalyst

\section{Introduction}

The increasing development of environmentally friendly energy sources and the search for new ones such as the sun, hydrogen, biomass [1] has had a negative impact on the price and global demand for oil and natural gas used for fuel production. This has become a challenge for the oil producing industry since a large group of chemicals can still be obtained from oil and natural gas only. Thus, despite of the intensified studies on the possibility to obtain the benzene, toluene, and xylene (BTX) fraction from alternative sources such as plastic waste as well as bio oil components [2-6], oil resources are still the primary method of BTX fraction recovery [7-9]. The demand for aromatic hydrocarbons and BTX fraction as their primary source has been increasing from year to year because of the consistently growing polymers market. The main sources of the BTX fraction today are reforming and the process is mainly known as the "steam cracking." Benzene, toluene, and xylene (BTX) are widely used as the feedstock for the industrial production of chemicals. In its turn, heavy oil fractions rich in polyaromatic compounds (that originate also from the both catalytic reforming and the naphtha steam cracking) can be used for the BTX production $[10,11]$.

Because of the increasing demand for low molecular weight olefins, the number of steam cracking facilities has increased as well. The annual average growth of ethylene and propylene consumption exceeds $4 \%$. Steam cracking capacity will continue to grow driven by ethylene/propylene demand. This process results in a large number of aromatic compounds and low-value waste in the form of pyrolysis fuel oil (PFO). PFO is used as a component of boiler fuel oil, or for the production of petroleum resins. PFO is not currently being recycled properly. Residual fractions of the pyrolysis process, in particular pyrolysis fuel oil (PFO), can be used for the BTX production. As PFO consists mainly of 
diaromatic compounds such as naphthalene (35.98\%), its ethyl-substituted equivalents of naphthalene $(10.95 \%)$ and biphenyl $(27.97 \%)$, it could be considered as a promising feedstock for the hydrocracking process that yields valuable products, such as gasoline or aromatics [12,13]. The hydrocracking of heavy oil residues is the wide-spread method used to lighten the composition of heavy oil residues and obtain a more valuable feedstock [14-17].

Supported metal catalysts are generally used as hydrocracking catalysts. Molybdenum or tungsten is used as an active metal. The catalysts are active in their sulfide form, with nickel or cobalt used as promoting substances. Acid materials such as zeolites, other aluminosilicates, or aluminum oxide are used as support [18-22]. Some studies describe the influence of oxide substrates on hydrogenation, hydrodesulfuration, and hydrocracking, stating that aluminum oxide-supported systems have a higher reactivity during hydrogenation [23-25]. Publications describe successful examples of the recovery of a commercially valuable BTX fraction from light catalytic gas oil (LCGO) on supported $\mathrm{NiMo} / \mathrm{Al}_{2} \mathrm{O}_{3}$ catalysts, with a BTX fraction yield of 44 to $70 \mathrm{wt} \%$ [26]. In this case, the average yield of the BTX fraction varies from $15 \%$ to $50 \%$ when obtained through pyrolysis [2,6], and from $20 \%$ to $50 \%$ when obtained through hydrocracking $[9,27]$.

Unsupported sulfide catalysts have been gaining popularity recently during studies of hydroprocessing in oil refining. This is due to their high catalytic reactivity as compared to supported hydrotreating catalysts $[28,29]$, as well as their ability to offer a solution for the active center's deactivation problem caused by the deposition of coke and condensation products [30,31].

Unsupported sulfide catalysts on the basis of transition metals can be obtained using different methods: coacervation [32], codeposition [33], or precursor decomposition [34-36]. Precursors can include water-soluble [34,35] and oil-soluble [36] transition metal compounds. Despite the fact that the use of water-soluble compounds is more cost effective because of their low cost, they entail the formation of somewhat larger particles, which reduces the reactivity of the obtained catalyst [37]. Dispersed Ni (Co) $-\mathrm{W}(\mathrm{Mo})-\mathrm{S}$ sulfide catalysts synthesized through in situ decomposition of various precursors are stable and characterized by high dispersiveness and a highly developed external surface [38].

Comparison of the reactivity of $\mathrm{MoS}_{2}$ and $\mathrm{WS}_{2}$ sulfide catalysts generated in situ from oil-soluble precursors during the hydrocracking of heavy residues has demonstrated the advantage of tungsten catalysts over molybdenum ones. $\mathrm{WS}_{2}$ was more dispersive and demonstrated a higher hydrogenating reactivity as compared to the molybdenum equivalent [39].

As was established previously, the Ni-W-S catalyst exhibits reactivity in the course of coking resin hydrogenation. The optimal temperature of the pyrolysis oil hydrotreatment is $380^{\circ} \mathrm{C}$. It provides for the minimum amount of bicyclic and polycyclic aromatic hydrocarbons, and ensures no thermal cracking process. [40].

Previously, the hydrocracking of hydrocarbon fractions in the presence of the in situ generated catalysts was described in the works [41-45]. However, to the best of our knowledge, there are no precedents for the use of a bifunctional nanoheterogeneous catalytic system to obtain the BTX fraction from the pyrolysis fuel oil.

In continuation of work on the study of the regularities of hydrogenation of aromatized hydrocarbon fractions in the presence of nanosized in situ formed sulfide catalysts $[35,46]$.

We offer a fundamentally new design opportunity for a quasi-homogeneous bifunctional catalytic system that can solve the problem of obtaining BTX from a pyrolysis fuel oil.

This study demonstrates the possibility of the use of the unsupported NiWS-HY catalysts generated in situ in the hydrocarbon feedstock from such oil-soluble precursors as tungsten hexacarbonyl $\left(\mathrm{W}(\mathrm{CO})_{6}\right)$ and Nickel(II)2-ethylhexanoate $\left(\mathrm{Ni}\left(\mathrm{C}_{7} \mathrm{H}_{15} \mathrm{COO}\right)_{2}\right)$ with $\mathrm{HY}$ zeolite addition for the selective recovery of the BTX fraction from pyrolysis fuel oil. 


\section{Results}

\subsection{Catalytic Properties}

\subsubsection{Naphthalene Hydrocracking with NiWS-HY Catalysts}

The reactivity of in situ generated catalysts as well as the possibility of the BTX fraction selective recovery were studied by the example of a model feedstock, for which purpose $10 \%$ solution of naphthalene in hexadecane was chosen as the feed mixture. The study was carried out in an autoclave-type batch reactor at $\mathrm{P}=5 \mathrm{MPa}, \mathrm{t}=5 \mathrm{~h}$, and $\mathrm{W}: \mathrm{Ni}$ ratio $=1: 2$. With a view to identifying the influence of temperature on product composition and conversion, experiments on in situ generated NiWS-HY catalyst were conducted at $350{ }^{\circ} \mathrm{C}, 380{ }^{\circ} \mathrm{C}$, and $400{ }^{\circ} \mathrm{C}$ by varying the zeolite content at a level of $0.5 \mathrm{wt} \%$ and $1 \mathrm{wt} \%$, and tungsten content at a level of $1 \mathrm{wt} \%, 2 \mathrm{wt} \%$, and $4 \mathrm{wt} \%$. Blank test showed that hexadecane does not react in these conditions.

The conversion of naphthalene under the selected conditions (Figure 1) was high and reached $84 \%-93 \%$.Temperature increase up to $400{ }^{\circ} \mathrm{C}$ resulted in 5 to $10 \%$ lower naphthalene conversion, which could be due to the specifics of Ni-W-S hydrogenating phase formation on the zeolite surface [47]. It should be as well noted, that the decrease in the conversion of naphthalene with increasing temperature does not contradict the thermodynamic laws of the hydrogenation reaction of this compound.

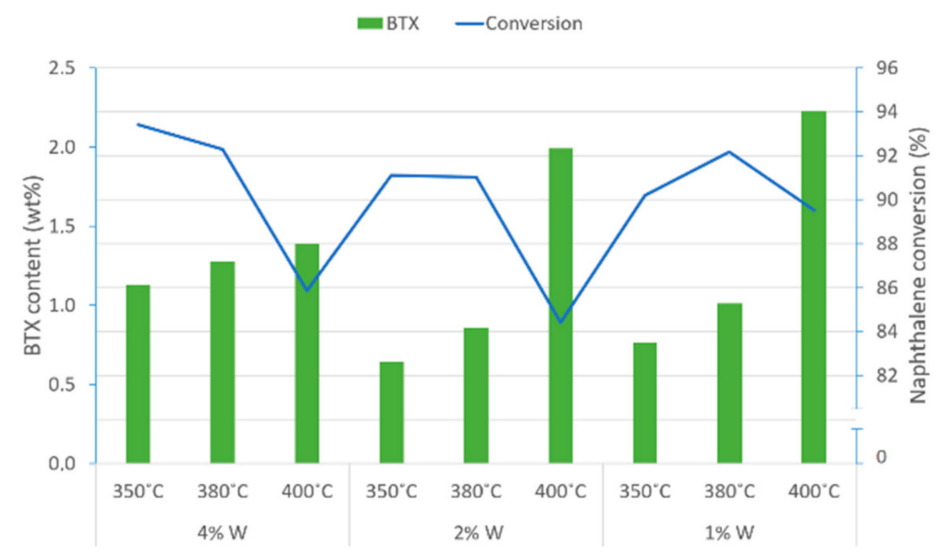

(a)

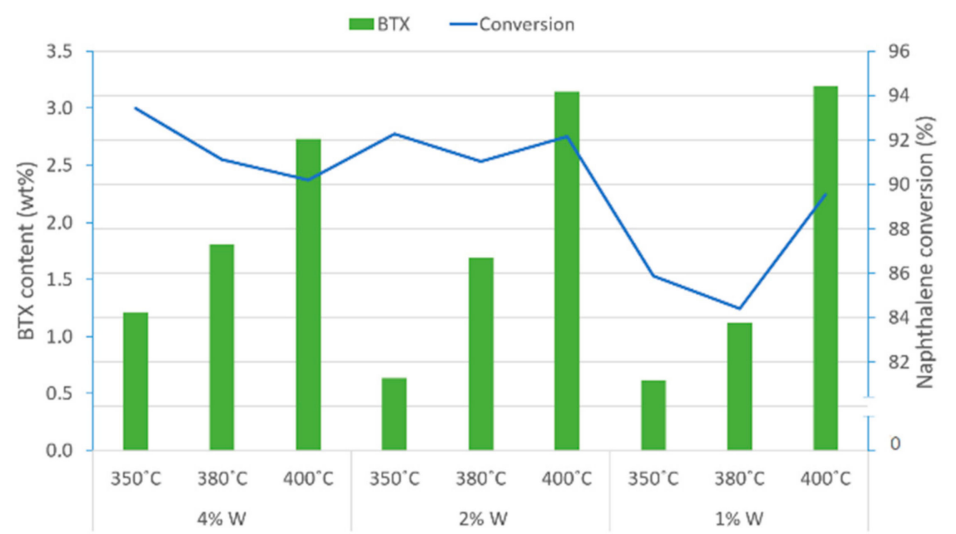

(b)

Figure 1. Naphthalene conversion versus tungsten molar ratio and reaction temperature, and benzene, toluene, and xylene (BTX) selectivity with (a) NiWS-HY(0.5\%), (b) NiWS-HY(1\%) catalysts at standard conditions $\mathrm{P}=5 \mathrm{MPa}, \mathrm{t}=5 \mathrm{~h}$, and $\mathrm{W}: \mathrm{Ni}$ ratio $=1: 2$. 
It can be seen from the graph of Figure 1 that the highest conversion is achieved on the average at $380{ }^{\circ} \mathrm{C}$ and a tungsten content of $4 \mathrm{wt} \%$ [46]. No significant changes in naphthalene conversion versus NiWS-HY $(0.5 \%)$ or NiWS-HY(1\%) zeolite content were revealed.

The sum of the benzene, toluene, and xylenes recovered during the hydrocracking process is about 2 to $3.5 \%$. The highest BTX yield were obtained at $400{ }^{\circ} \mathrm{C}$ and a weight content of $1 \%$ for zeolite and $4 \%$ for tungsten (Figure 2). Under these conditions, in a mixture of xylenes, the ratio m-xylene:p-xylene = $1: 10$, and o-xylene is formed in trace amounts. We used these results to identify the dependencies of BTX components of selectivity on temperature and tungsten content (Figure 2). As a result, the highest benzene content as compared to xylene and toluene is observed.

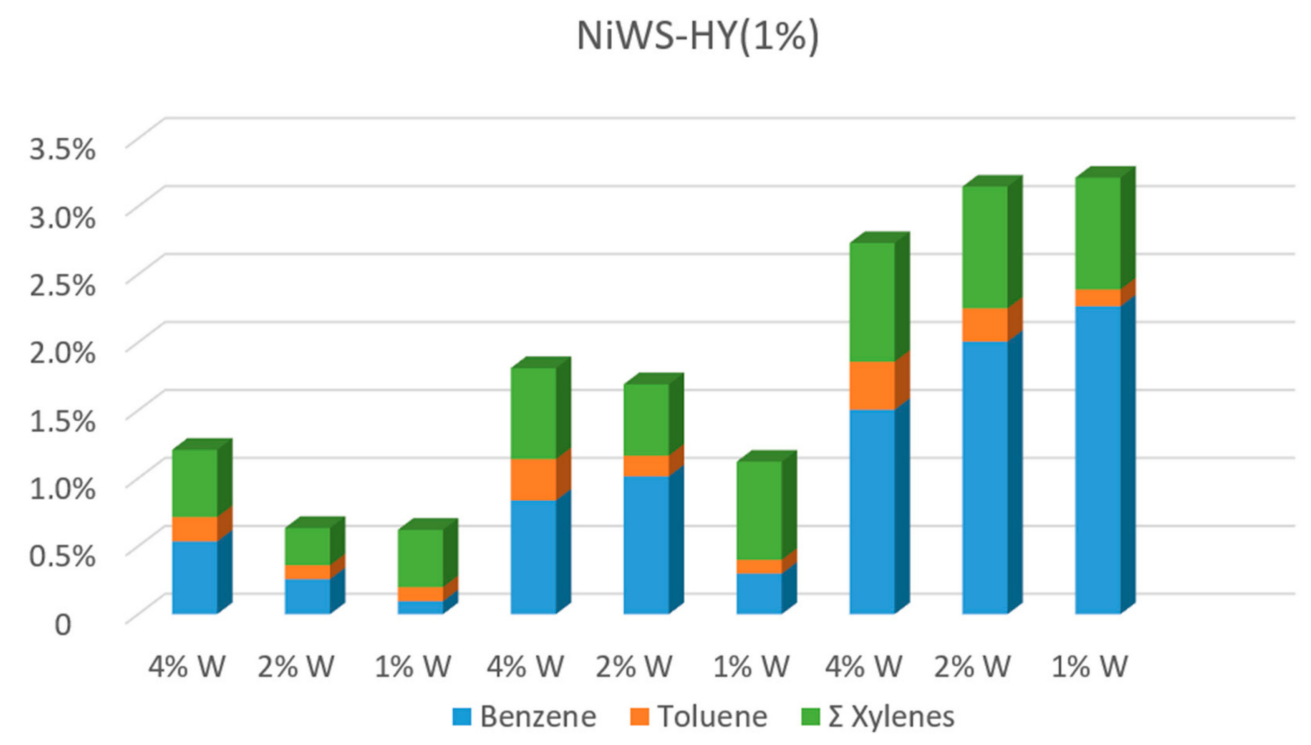

Figure 2. BTX (benzene, toluene, xylene) components selectivity in hydrocracking reaction of naphthalene solution with NiWS-HY(1\%) catalysts at standard conditions $\mathrm{P}=5 \mathrm{MPa}, \mathrm{t}=5 \mathrm{~h}$, and W:Ni ratio $=1: 2$.

At the same time, the main products of naphthalene hydrocracking under these conditions are tetralin and decalin. The higher their temperature, the lower their content in the reaction products, and the higher the BTX fraction content. The reaction is probably of consecutive behavior, with the tetralin acting as an intermediate. Scheme 1. If the hydrogenation rate is higher than the tetralin cracking rate, tetralin is accumulated and then hydrogenated to yield decalins. In a different scenario, tetralin is not generated at all $[9,27]$.

Considering the hydrocracking results for a model mixture and preceding experience of the colleagues, the best hydrocracking results for the PFO fraction are expected when NiWS-HY $(1 \%)$ is used since a high degree of feedstock conversion can probably be achieved when $1 \mathrm{wt} \%$ of zeolite is added [48], at $380^{\circ} \mathrm{C}$ to $400{ }^{\circ} \mathrm{C}$, and a tungsten content of $4 \%$ (Table 1). 


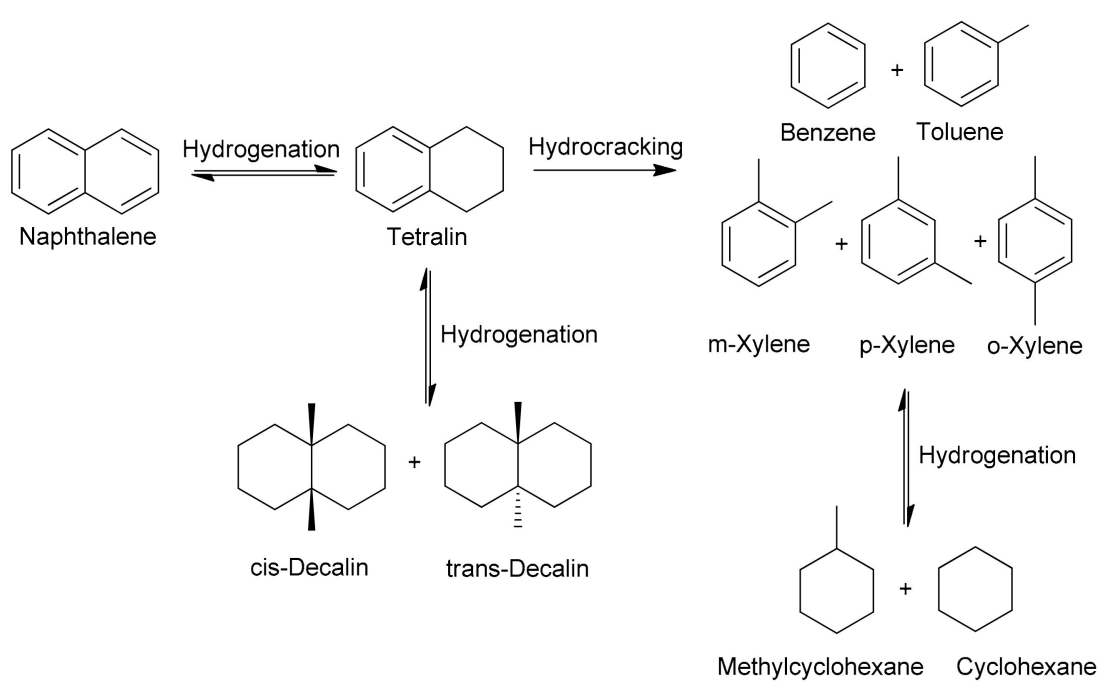

Scheme 1. Hydrocracking of pyrolysis fuel oil components into BTX.

Table 1. Detailed composition of naphthalene hydrocracking products for NiWS-HY(1\%), $\mathrm{W}=4 \%$ catalysts at standard conditions $\mathrm{P}=5 \mathrm{MPa}, \mathrm{t}=5 \mathrm{~h}$, and $\mathrm{W}: \mathrm{Ni}$ ratio $=1: 2$.

\begin{tabular}{cccc}
\hline Compound & Amount (wt \%) & Compound & $\begin{array}{c}\text { Amount } \\
\mathbf{( w t} \%)\end{array}$ \\
\hline Methylcyclopentane & 0.47 & Benzene & 2.84 \\
3-Methylhexane & 0.39 & Heptane & 0.24 \\
Methylcyclohexane & 0.37 & Dimethylhexane & 0.17 \\
4-Methylheptane & 0.5 & Toluene & 0.15 \\
3-Methylheptane & 0.92 & Octane & 0.12 \\
m-Xynene & 0.72 & p-Xynen & 0.06 \\
o-Xynene & 0.04 & Decals & 3.4 \\
Butylbenzene & 0.2 & Methylindanes & 13.14 \\
Tetralin & 63.81 & - & - \\
\hline
\end{tabular}

\subsubsection{Pyrolysis Fuel Oil Hydrocracking with NiWS-HY Catalysts}

The reactivity of in situ generated NiWS-HY $(0.5 \%)$ and NiWS-HY $(1 \%)$ catalysts during pyrolysis fuel oil hydroconversion was studied in an autoclave-type batch reactor at standard conditions $p=5 \mathrm{MPa}, \mathrm{t}=5 \mathrm{~h}$, and ratio $\mathrm{W}: \mathrm{Ni}=1: 2$, initial hydrogen pressure in the reaction system of $5.0 \mathrm{MPa}$, with intensive stirring. An HPR fraction with an upper boiling point of $330^{\circ} \mathrm{C}$, whose characteristics are given in Materials and Methods section, was used as a starting material.

To determine the optimal process temperature, we compared the active NiWS-HY(1\%) and NiWS-HY $(0.5 \%)$ catalysts with constant mass content $\mathrm{W}=4 \%$. Table 2 shows the BTX (benzene, toluene, xylene) selectivity between the reaction temperature and zeolite weight percentage. It was demonstrated that the in situ generated NiWS-HY(1\%) catalyst is more active in the hydrocracking reaction than NiWS-HY $(0.5 \%)$. The best selectivity of the BTX fraction was obtained at $380{ }^{\circ} \mathrm{C}$. Maximum selectivity of BTX reaches $15 \mathrm{wt} \%$.

When comparing the amount of the light fraction (with a boiling temperature up to $180{ }^{\circ} \mathrm{C}$ ) generated at a different zeolite content, the predictably better results were obtained at a higher zeolite content (1 wt \%) (Figure 3) [49]. The resulting light fraction also contains other valuable compounds. 
Table 2. Dependence between component composition of the BTX fraction and temperature at standard conditions.

\begin{tabular}{|c|c|c|c|c|c|c|}
\hline \multirow{2}{*}{ Catalyst } & \multirow{2}{*}{ Process Conditions } & \multirow{2}{*}{$W(w t \%)$} & \multicolumn{4}{|c|}{ BTX Composition (wt \%) } \\
\hline & & & Benzene & Toluene & Xylenes & $\Sigma \mathrm{BTX}$ \\
\hline \multirow{3}{*}{ NiWS-HY(0.5\%) } & $350^{\circ} \mathrm{C}$ & \multirow{6}{*}{4.0} & 3.3 & 2.5 & 0.8 & 6.6 \\
\hline & $380^{\circ} \mathrm{C}$ & & 7.7 & 2.2 & 0.95 & 10.85 \\
\hline & $400{ }^{\circ} \mathrm{C}$ & & 5 & 0.7 & 1.1 & 6.8 \\
\hline \multirow{3}{*}{ NiWS-HY(1\%) } & $350^{\circ} \mathrm{C}$ & & 5.4 & 2.2 & 1.5 & 9.1 \\
\hline & $380^{\circ} \mathrm{C}$ & & 9.5 & 3.7 & 1.8 & 15 \\
\hline & $400^{\circ} \mathrm{C}$ & & 3.3 & 4.1 & 2.3 & 9.7 \\
\hline
\end{tabular}

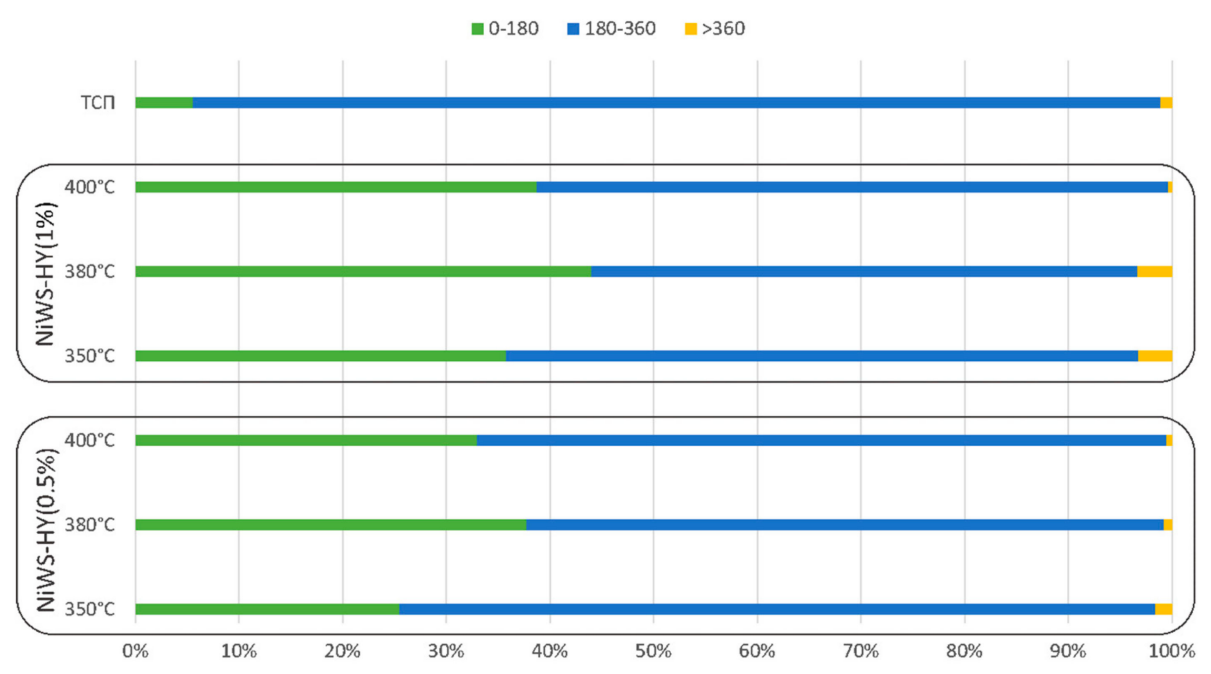

Figure 3. Fractional composition of HPR hydrocracking products with NiWS-HY(0.5\%), NiWS-HY(1\%) catalysts at constant mass content $\mathrm{W}=4 \%$ and at standard conditions $(p=5 \mathrm{MPa}, \mathrm{t}=5 \mathrm{~h}$, and $\mathrm{W}: \mathrm{Ni}$ ratio $=1: 2$ ).

It is also noteworthy that PFO hydrocracking yields were 8-10 wt \% in the reaction mass of cyclohexane as one of the benzene hydrogenation products. The cyclohexane is a non-toxic intermediate compound, which is widely used for the production of nylons and caprolactam. Currently, the greatest part of the world's cyclohexane production is based on benzene hydrogenation [50].

If we consider the dependence of the component composition of BTX reaction products (Table 3) on the cat/raw material ratio, we can note that the selectivity of benzene formation in the mixture increases with an increasing of wt \% of tungsten, while selectivity of xylenes formation, on the contrary, increases with a decreasing of the amount of tungsten.

Table 3. Fractional composition of reaction products versus catalyst/feedstock ratio and zeolite content at $380{ }^{\circ} \mathrm{C}$ with NiWS-HY(0.5\%), NiWS-HY $(1 \%)$ catalysts at standard conditions $\mathrm{P}=5 \mathrm{MPa}, \mathrm{t}=5 \mathrm{~h}$, and $\mathrm{W}: \mathrm{Ni}$ ratio $=1: 2$.

\begin{tabular}{ccccccccc}
\hline \multirow{2}{*}{\begin{tabular}{c}
\multirow{2}{*}{ Catalyst } \\
\end{tabular}} & \multirow{2}{*}{ W (wt \%) } & \multicolumn{3}{c}{ Fractional Composition $\mathbf{( w t} \%)$} & \multicolumn{4}{c}{ BTX Composition (wt \%) } \\
\cline { 3 - 9 } & & $\mathbf{0}$ to $\mathbf{1 8 0}$ & $\mathbf{1 8 0}$ to $\mathbf{3 6 0}$ & $\mathbf{> 3 6 0}$ & Benzene & Toluene & Xylenes & $\boldsymbol{\Sigma}$ BTX \\
\hline \multirow{2}{*}{ NiWS-HY(1\%) } & 4.0 & 44 & 52.7 & 3.3 & 9.5 & 3.7 & 1.8 & 15 \\
& 2.0 & 28.9 & 67.5 & 3.6 & 5.9 & 2.6 & 1.8 & 10.3 \\
& 1.0 & 24.2 & 72.4 & 3.34 & 3.9 & 2.5 & 2.1 & 8.5 \\
NiWS-HY(0.5\%) & 4.0 & 37.7 & 61.5 & 0.8 & 7.7 & 2.2 & 1 & 10.9 \\
& 2.0 & 33 & 65.2 & 1.8 & 7.3 & 1 & 1.2 & 9.5 \\
& 1.0 & 31.8 & $68 \%$ & 0.2 & 5.4 & 1.8 & 2.1 & 9.3 \\
\hline
\end{tabular}


The fractional composition of TSP after hydrocracking changes noticeably, the amount of the fraction with boiling points of $0-180^{\circ} \mathrm{C}$ increases almost ten times, and it contains about $15 \mathrm{wt} \%$ of valuable components of BTX fraction (benzene-toluene-xylenes). The fraction with boiling points of $180-360^{\circ} \mathrm{C}$ contains more than $30 \mathrm{wt} \%$ of decalins and tetralin.

\subsection{Catalyst Properties}

As is known, the activity of supported sulfide catalysts depends on the degree of sulfidation of the catalyst and the promoter/nickel ratio. The degree of sulfidation also depends on the temperature. The phases of nickel sulfide (NiS) and oxosulfide tungsten $\left(\mathrm{WO}_{\mathrm{x}} \mathrm{S}_{\mathrm{y}}\right)$ are formed on a support structure at $300-400{ }^{\circ} \mathrm{C}$. The higher the degree of interaction with the support, the more difficult the sulfidation of the oxysulfide phase and the formation of a mixed Ni-W-S phase are [49].

Based on the results of XPS, we revealed some dependences of the formed catalyst. We analyzed two catalysts obtained in situ in real raw material (pyrolysis fuel oil) at different zeolite/raw material ratios $(0.5 \%$ and $1 \%)$ with catalyst sulfurization with elemental sulfur in the reaction medium (Tables 4 and 5). The best results for the selectivity of BTX fraction were showed with a tungsten content of $4 \mathrm{wt} \%$ at standard conditions ( $p=5 \mathrm{MPa}, \mathrm{t}=5 \mathrm{~h}$, and $\mathrm{W}$ : Ni ratio $=1: 2)$. The results of XPS obtained by us are consistent with the literature [51] since the signals of oxygen, carbon, sulfur, nickel, and tungsten correspond to characteristic signals of nickel-tungsten-sulfide catalysts. Promotion coefficient of NiWS-HY $(0.5 \%)$ catalyst is 0.34 , and promotion coefficient of NiWS-HY $(1 \%)$ catalyst is only 0.19 , Figure 4.

Table 4. XPS data for W4f, Ni2p, and S2p levels (catalyst obtained by decomposition of precursors with different concentrations of added zeolite) are $0.5 \%$ and $1 \%-\mathrm{HY}$ in standard conditions.

\begin{tabular}{|c|c|c|c|c|c|c|c|c|}
\hline \multirow{3}{*}{\multicolumn{2}{|c|}{ Element }} & \multicolumn{7}{|c|}{ Status } \\
\hline & & \multicolumn{3}{|c|}{ NiWS-HY(0.5\%) } & \multicolumn{3}{|c|}{ NiWS-HY(1\%) } & \multirow[b]{2}{*}{ Status } \\
\hline & & $\begin{array}{l}\text { Binding Energy, } \\
\mathrm{eV}\end{array}$ & $\begin{array}{c}\text { Weight } \\
\%\end{array}$ & $\underset{\%}{\text { Atomic }}$ & $\begin{array}{l}\text { Binding Energy, } \\
\mathrm{eV}\end{array}$ & $\begin{array}{c}\text { Weight } \\
\%\end{array}$ & $\underset{\%}{\operatorname{Atomic}}$ & \\
\hline \multirow{5}{*}{ W4f } & $\begin{array}{l}4 \mathrm{f} 7 / 2 \\
\text { 4f } 5 / 2\end{array}$ & $\begin{array}{c}33 \\
35.1\end{array}$ & 65.6 & 3.5 & $\begin{array}{l}33.2 \\
35.3\end{array}$ & 52.53 & 2.77 & $\mathrm{WS}_{2}$ \\
\hline & $4 f 7 / 2$ & 33.4 & \multirow{2}{*}{21.7} & \multirow[b]{2}{*}{1.2} & 33.5 & \multirow{2}{*}{30.01} & \multirow[b]{2}{*}{1.58} & \multirow{2}{*}{ WOxSy } \\
\hline & 4f $5 / 2$ & 35.5 & & & 35.8 & & & \\
\hline & $4 \mathrm{f} 7 / 2$ & 36.7 & \multirow{2}{*}{12.8} & \multirow{2}{*}{0.7} & 37 & \multirow{2}{*}{13.88} & \multirow{2}{*}{0.73} & \multirow{2}{*}{$\mathrm{WO}_{3}$} \\
\hline & 4f $5 / 2$ & 38.5 & & & 38.7 & & & \\
\hline \multirow{6}{*}{$\mathrm{Ni} 2 \mathrm{p}$} & $2 \mathrm{p} 3 / 2$ & 854.9 & \multirow{2}{*}{48.3} & \multirow{2}{*}{1.64} & 854.7 & \multirow{2}{*}{42.25} & \multirow{2}{*}{0.80} & \multirow[b]{2}{*}{$\mathrm{NiS}$} \\
\hline & $2 \mathrm{p} 1 / 2$ & 874.8 & & & 874.7 & & & \\
\hline & $2 \mathrm{p} 3 / 2$ & 857 & \multirow{2}{*}{34.5} & \multirow{2}{*}{1.17} & 856.6 & \multirow{2}{*}{28.09} & \multirow{2}{*}{0.53} & \multirow{2}{*}{ Ni-W-S } \\
\hline & $2 \mathrm{p} 1 / 2$ & 877.6 & & & 877 & & & \\
\hline & $2 \mathrm{p} 3 / 2$ & 858.7 & \multirow{2}{*}{17.3} & \multirow{2}{*}{0.59} & 858.4 & \multirow{2}{*}{29.67} & \multirow{2}{*}{$0.5 \%$} & \\
\hline & $2 \mathrm{p} 1 / 2$ & 879.8 & & & 880 & & & $\mathrm{NiO}$ \\
\hline & $2 \mathrm{p} 3 / 2$ & 162.6 & 74.6 & 12.6 & 162.7 & 77.80 & 13.04 & $\mathrm{~S}^{2-}$ \\
\hline S2p & $2 \mathrm{p} 3 / 2$ & 163.9 & 14.2 & 2.4 & 164 & 12.94 & 2.17 & $\mathrm{~S}_{2}{ }^{2-}$ \\
\hline & $2 \mathrm{p} 3 / 2$ & 167.9 & 10.4 & 1.8 & 168 & 9.26 & 1.55 & $S^{6+}$ \\
\hline
\end{tabular}

Table 5. Elemental composition of the catalyst surface according to XPS data.

\begin{tabular}{ccccccc}
\hline \multirow{2}{*}{ Catalyst } & \multicolumn{7}{c}{ Atomic \% } \\
\cline { 2 - 7 } & $\mathbf{C}$ & $\mathbf{W}$ & $\mathbf{N i}$ & $\mathbf{S}$ & $\mathbf{O}$ & $\mathbf{N}$ \\
\hline NiWS-HY(0.5\%) & 63.146 & 5.311 & 3.390 & 16.922 & 11.232 & - \\
NiWS-HY(1\%) & 66.637 & 5.273 & 1.891 & 16.763 & 9.436 & - \\
\hline
\end{tabular}




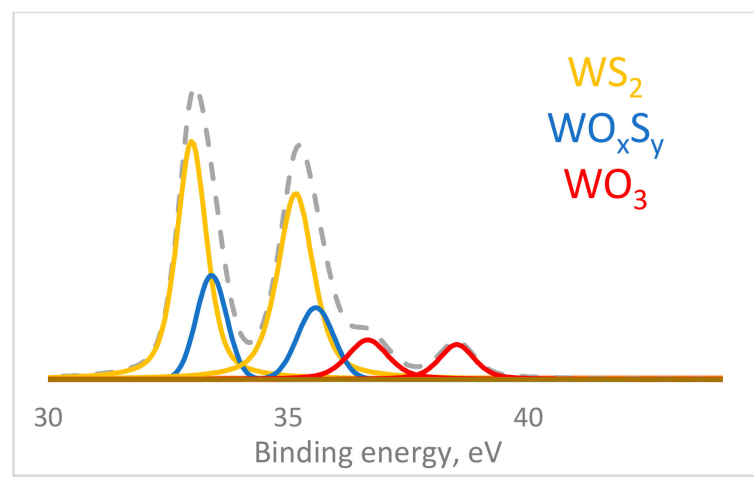

(a)

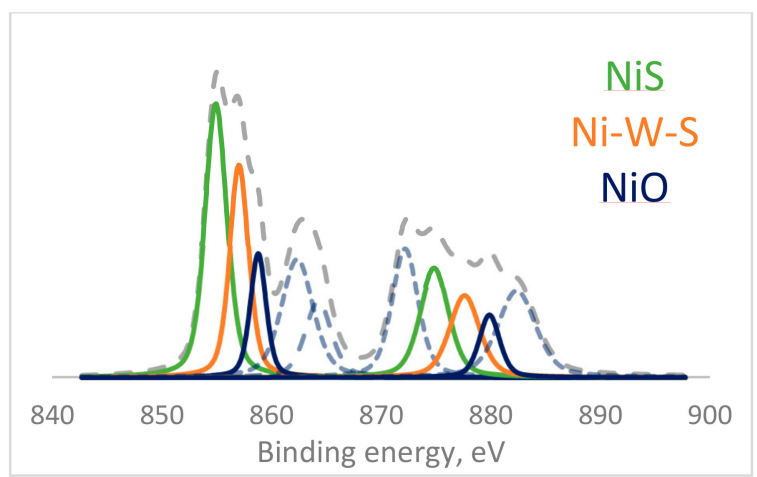

(b)

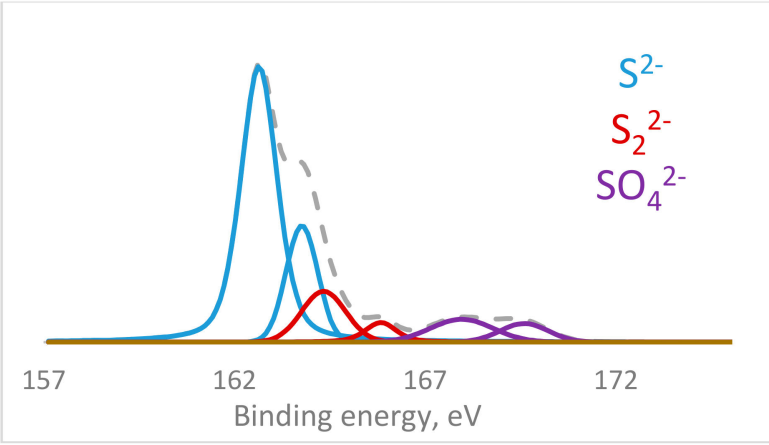

(c)

Figure 4. The (a) W 4f, (b) Ni 2p, and (c) S 2p XPS spectra of the NiWS-HY(0.5\%) sample.

Based on the XPS results, it can be concluded that the active Ni-W-S phase is more easily formed on zeolite surface at mass content of $0.5 \%$, which is reflected in the results of the catalytic experiment, and also in a larger amount of $\mathrm{WS}_{2}$. It is also known to contribute to the hydrogenation process. But its activity is much lower than that of the phase Ni-W-S [52].

In an attempt to explain the experimental data on the activity of catalysts in hydrocracking, we studied the morphology of in situ formed catalysts isolated after the reaction using transmission electron microscopy (TEM). It should be noted that, according to TEM data, catalysts prepared in situ with the addition of zeolites directly to the reaction medium are spherical agglomerates (Figure 5). Moreover, in a sample with a lower zeolite content, the spherical shape is more pronounced, the average size of a spherical particle is from 0.18 to $0.2 \mu \mathrm{m}$, and in a catalyst sample with a high zeolite content, the average size of spherical particles is from 0.2 to $0.24 \mu \mathrm{m}$. The number of layers in sulfide packs $(\mathrm{N})$ and the length of the stack (L) were determined manually. For the sample obtained with the addition of $0.5 \mathrm{wt} \%$ of zeolite, average $\mathrm{N}=4.7$, and $\mathrm{L}=3.3$, while obtained with the addition of $1 \mathrm{wt} \%$ of zeolite, $\mathrm{N}=2.8, \mathrm{~L}=6.2$. We calculated the dispersion of particles $\left(\mathrm{Ni}-\mathrm{WS}_{2}\right)$ according to the 
published method [51]. The dispersion of NiWS-HY (0.5\%) catalyst 0.23 and NiWS-HY (1\%) catalyst 0.2 was calculated.

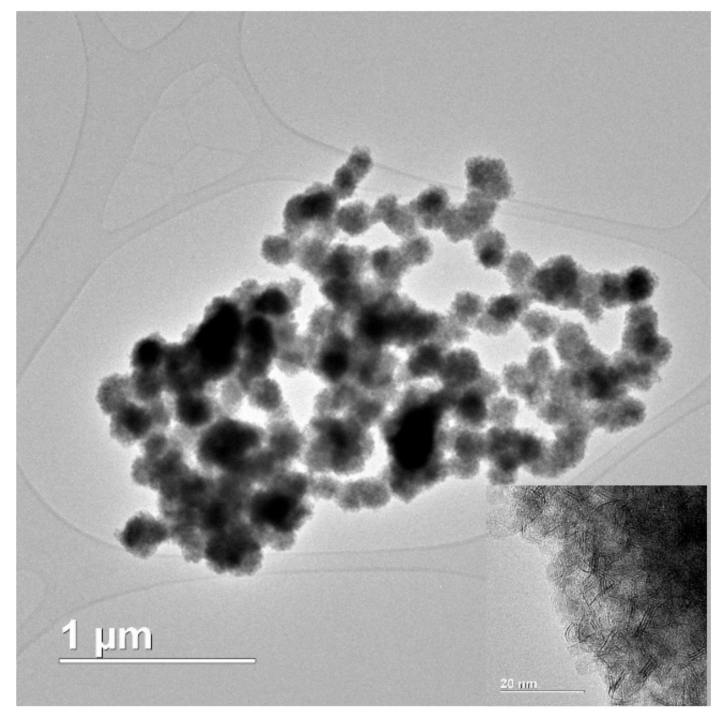

(a)

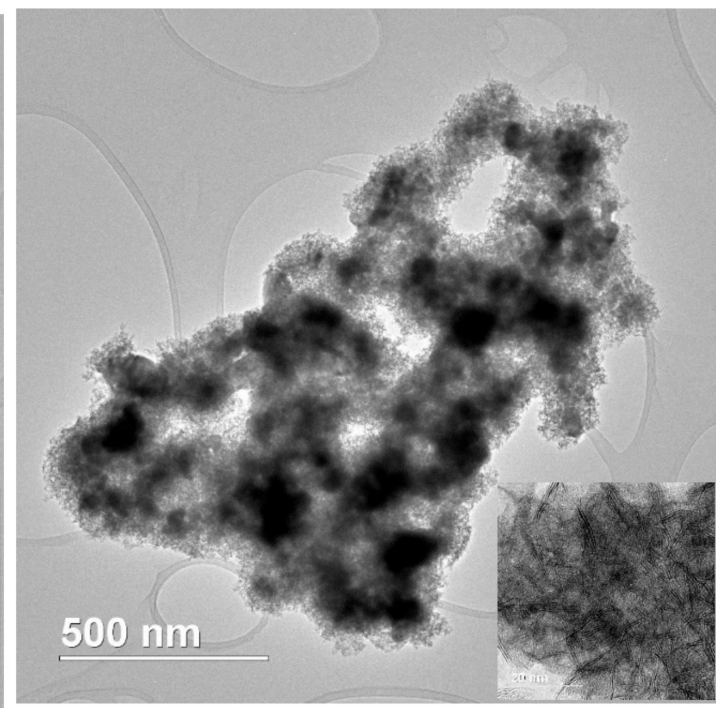

(b)

Figure 5. TEM micrograph of NiWS catalysts with (a) $0.5 \%$ and (b) $1 \%$ HY obtained in situ in standard conditions.

The size distribution of crystals of $\mathrm{Ni}-\mathrm{W}, \mathrm{NiSx}$, etc., larger than $5 \mathrm{~nm}$ can be determined by analyzing the images of element maps. These element maps confirm the results of XPS and indicate that a larger amount of the hydrogenating Ni-W-S phase is formed under the condition of a smaller addition $(0.5 \mathrm{wt} \%)$ of zeolite to the reaction medium. Thus, in this case, the results indicate the fact that the concentration of zeolite present in the mixture has a significant effect on the formation of the active phase.

Ni sulfide (NiSx) crystals are visible on TEM images and element maps of STEM-EDX and NiWS-HY $(0.5 \%)$ (Figure 6 and NiWS-HY (1\%) (Figure 7) hydrocracking catalysts. Particles range from about 5 to over $100 \mathrm{~nm}$ in diameter, all of them are surrounded with a Ni-W-S phase. As is known from the literature, a large amount of crystalline nickel sulfide does not contribute significantly to the hydrogenation process [53]. The distribution maps added to the article Appendix A (Figures A1 and A2).

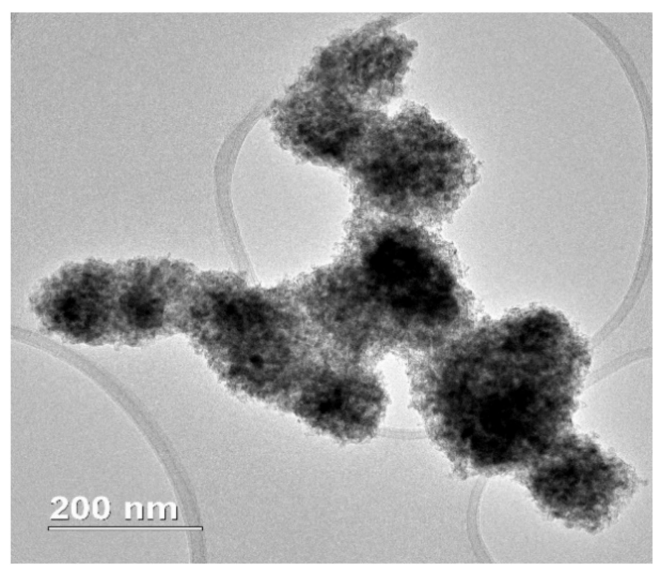

(a)

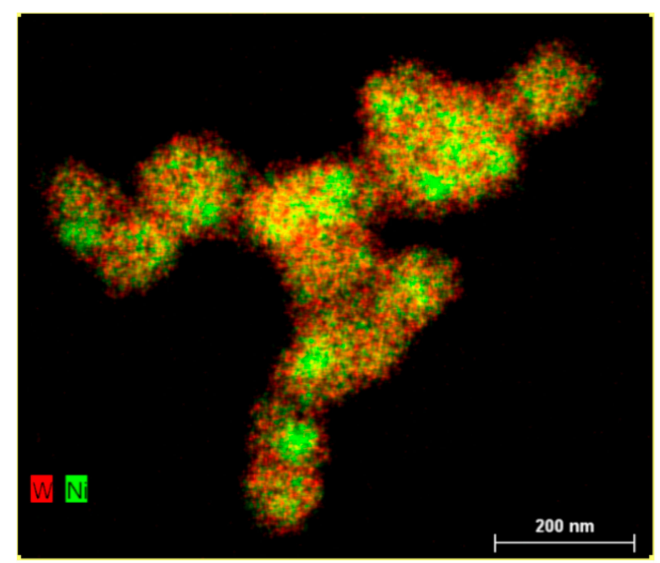

(b)

Figure 6. Cont. 


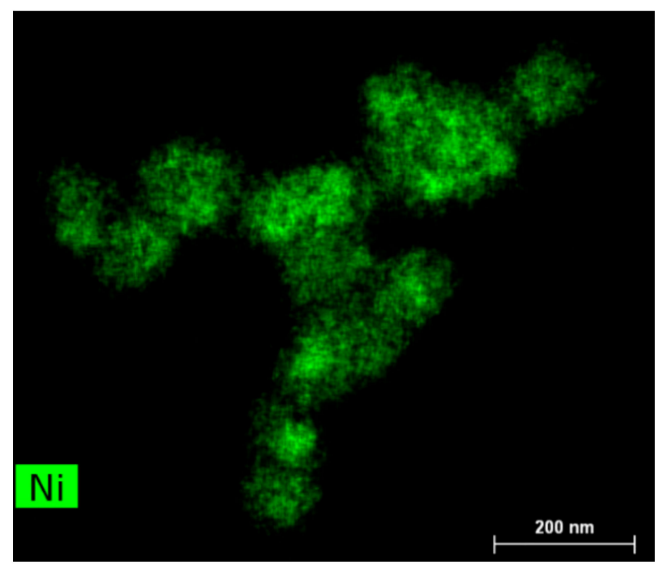

(c)

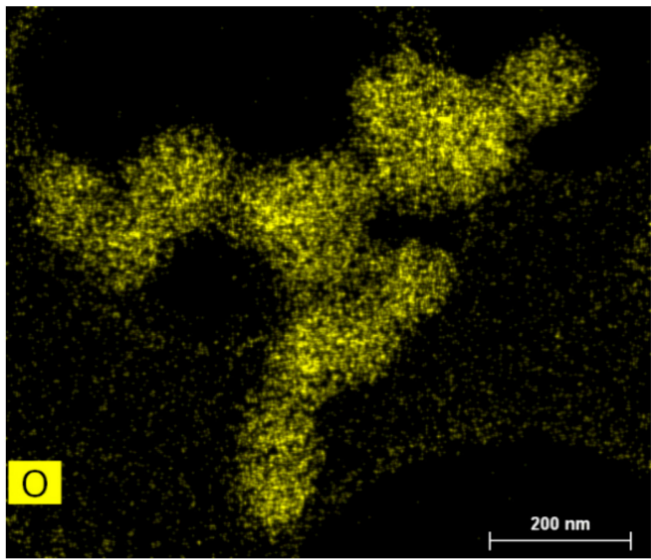

(e)

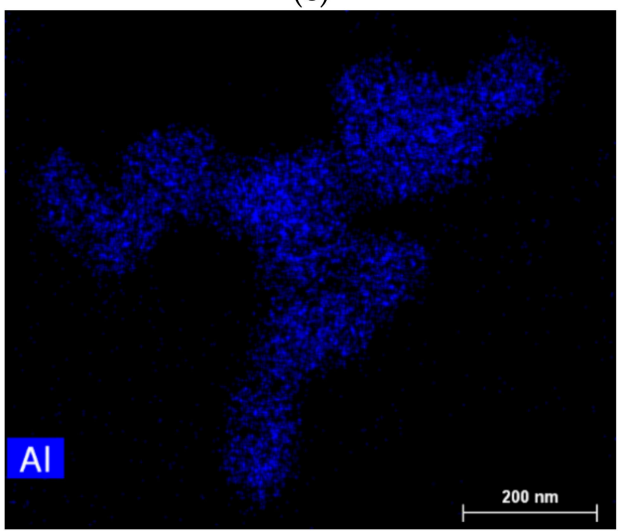

(g)

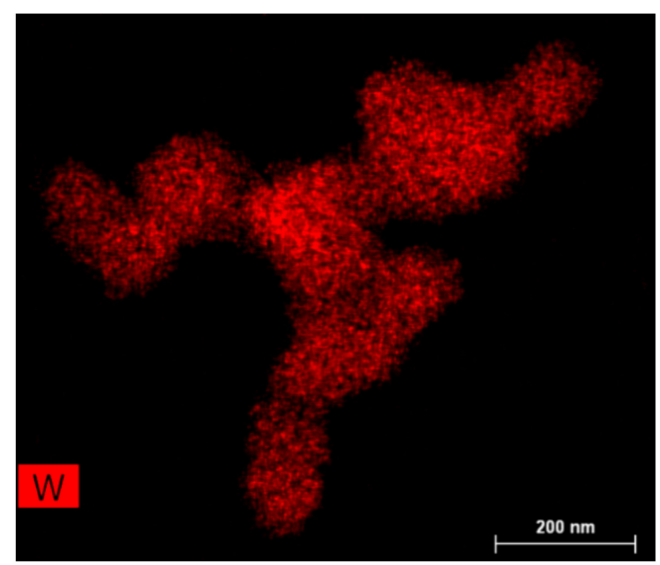

(d)

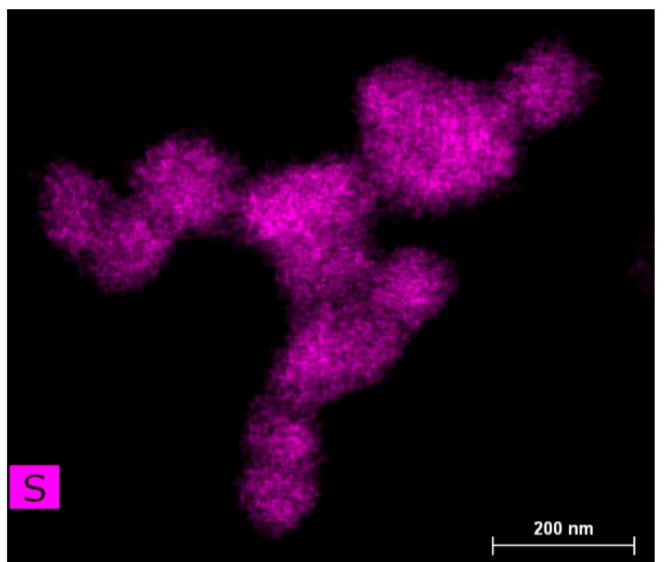

(f)

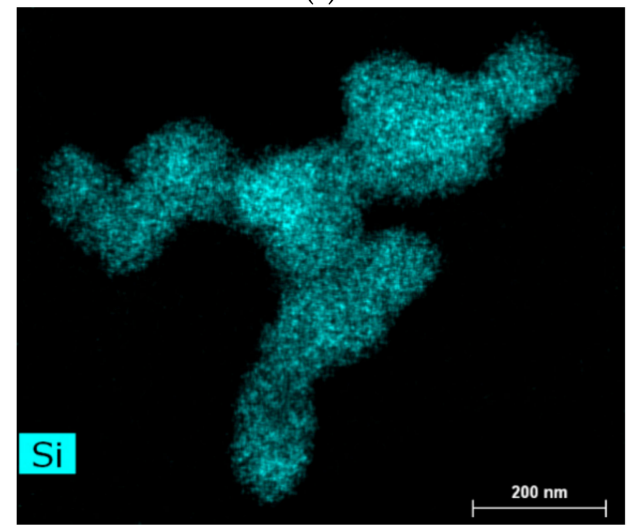

(h)

Figure 6. (a) TEM micrograph and distribution maps of NiWS-HY(0.5\%) elements (b) Ni-W, (c) Ni, (d) W, (e) $\mathrm{O}$, (f) $\mathrm{S}$, (g) Al, (h) Si obtained in situ in standard conditions. 


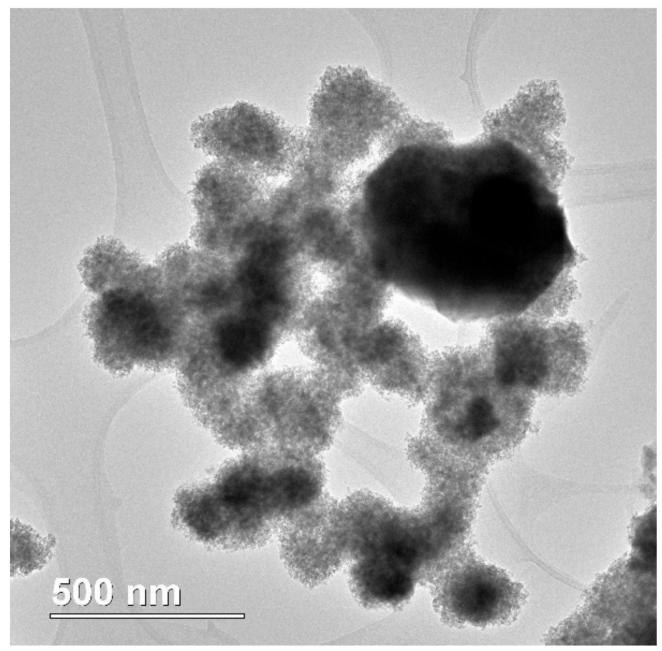

(a)

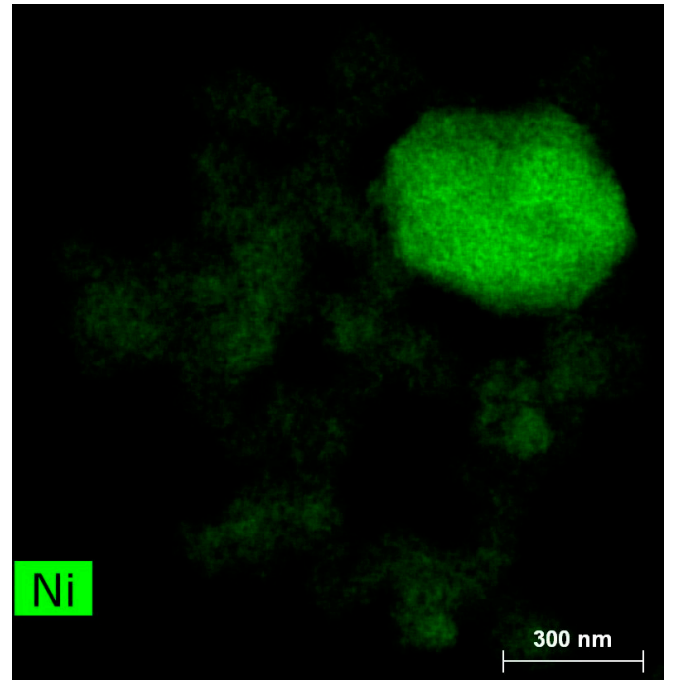

(c)

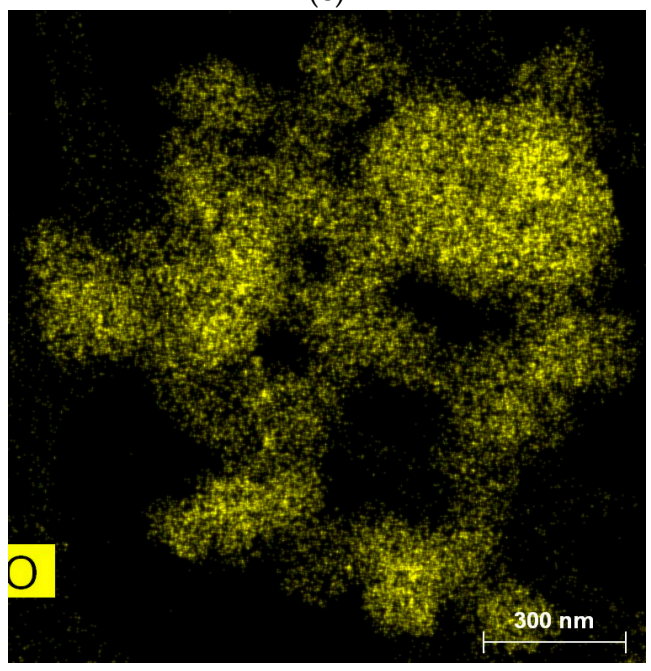

(e)

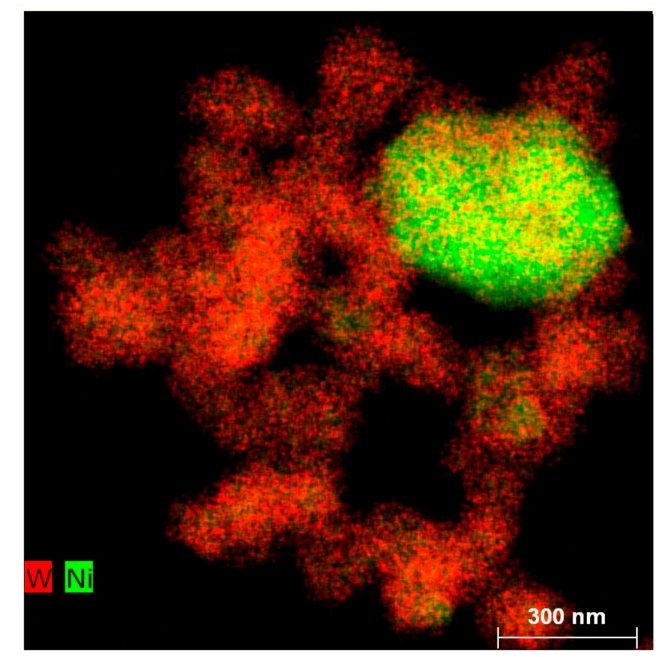

(b)

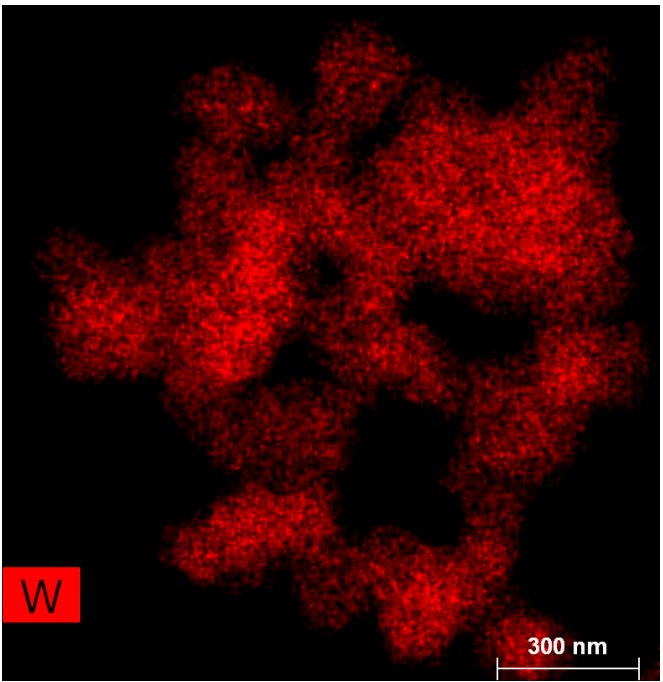

(d)

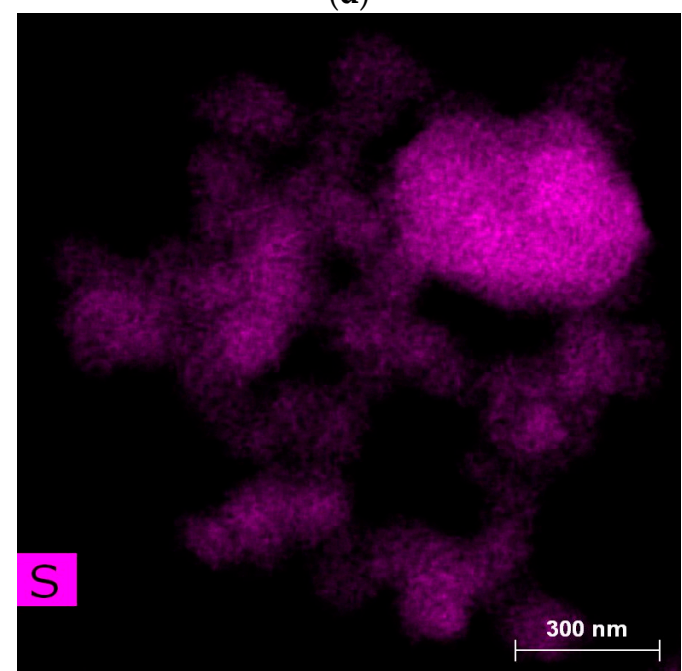

(f)

Figure 7. Cont. 


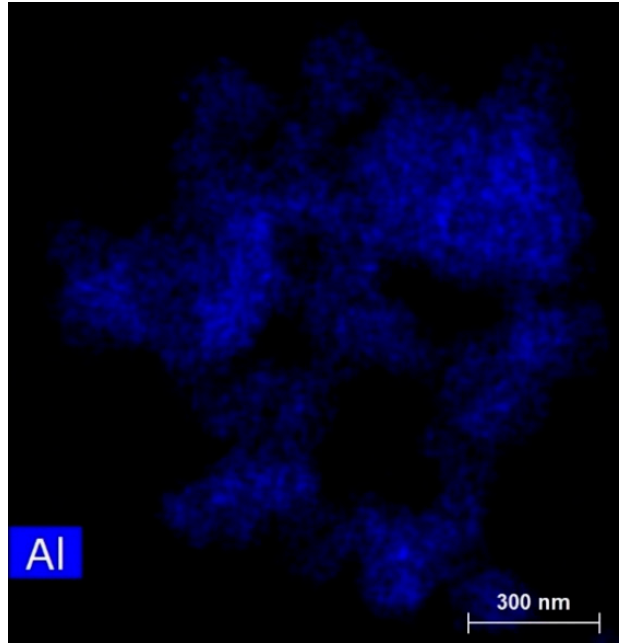

(g)

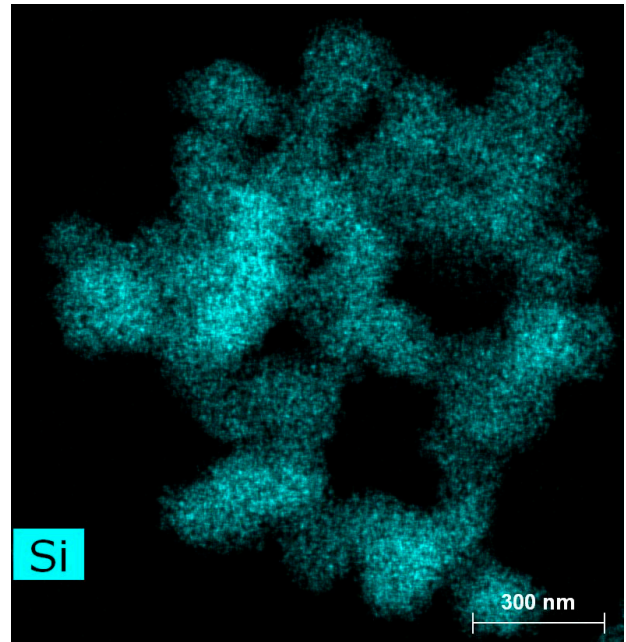

(h)

Figure 7. (a) TEM micrograph and distribution maps of NiWS-HY(1\%) elements (b) Ni-W, (c) Ni, (d) W, (e) $\mathrm{O}$, (f) $\mathrm{S}$, (g) Al, (h) Si obtained in situ in standard conditions.

\section{Materials and Methods}

\subsection{Materials}

Reagents used are tungsten hexacarbonyl $\mathrm{W}(\mathrm{CO})_{6}$ (99.99\%, Aldrich), nickel(II 2-ethylhexanoate $\mathrm{Ni}\left(\mathrm{C}_{7} \mathrm{H}_{15} \mathrm{COO}\right)_{2}(78 \%$ solution in 2-ethylhexanoic acid, Aldrich). A solution of naphthalene (99\%, Aldrich) in hexadecane ( $\geq 99 \%$, Aldrich) was used as a substrate.

The fraction of the pyrolysis fuel oil was obtained from the pyrolysis fuel oil produced by Sibur-Kstovo (Kstovo, Russia) by vacuum distillation with the selection of IBP $170{ }^{\circ} \mathrm{C}$ fraction (residual distillation pressure-2 Torr). The output of the distillate fraction was $75.4 \mathrm{wt} \%$, the boiling point reduced to atmospheric pressure was $330^{\circ} \mathrm{C}$. The composition shown in Figure 5 contains naphthalene (35.98\%), its methyl-substituted analogs (10.95\%), and biphenyl (27.97\%) (Figure 8).

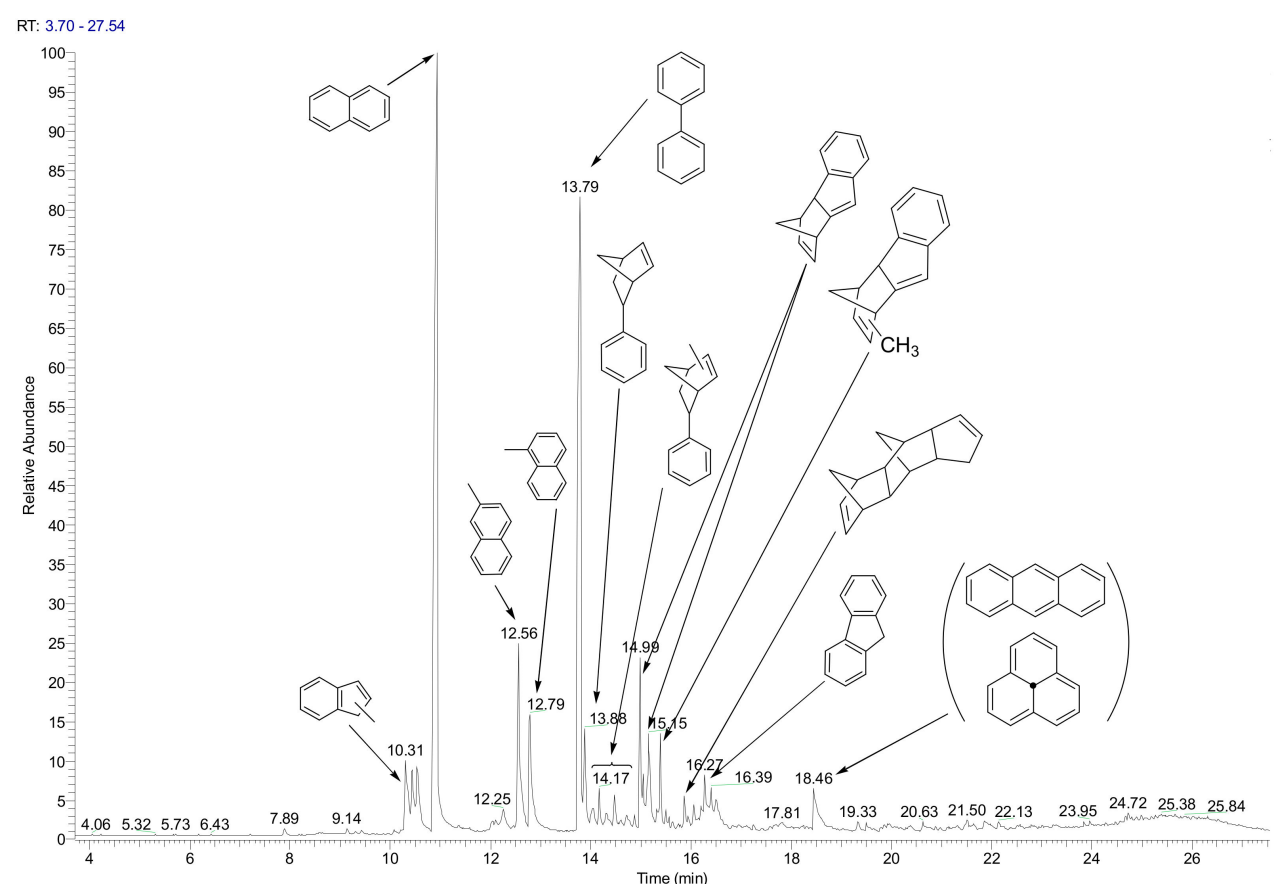

Figure 8. GC-MS plot of pyrolysis fuel oil fraction. 
The mass chromatogram of the fraction was obtained on a Finnigan MAT 95 XL instrument (Varian VF- $5 \mathrm{~ms}$ capillary column, length of $30 \mathrm{~m}$, inner diameter of $0.25 \mathrm{~mm}$, film thickness of $0.25 \mu \mathrm{m}$ ). All chemicals were used without preliminary purification.

\subsection{Catalyst Synthesis}

Sulfide catalysts of the NiWS-HY composition were prepared in situ in a hydrocarbon raw material. Low-soluble salts of hexacarbonyl tungsten $\mathrm{W}(\mathrm{CO})_{6}$ and nickel(II)2-ethylhexanoate $\mathrm{Ni}\left(\mathrm{C}_{7} \mathrm{H}_{15} \mathrm{COO}\right)_{2}$ were used as precursors. To form the hydrogenating component of the catalyst in the form of tungsten sulfide promoted with nickel, $2.5 \mathrm{wt}$. \% of elemental sulfur was added to the reaction mixture as a sulfiding agent. As the acidic component of the catalyst, a commercial wide-pore zeolite Y(CBV 600) with a three-dimensional porous structure and a channel diameter of $7.4 \AA$ and cavities of $12 \AA$ was chosen, which was added directly to the reaction medium. In zeolite molar ratio $\mathrm{SiO}_{2} / \mathrm{Al}_{2} \mathrm{O}_{3}=5.2$. According to TEM data particle size is $400-800 \mathrm{~nm}$. Specific surface area found by the low-temperature adsorption of nitrogen is $530 \mathrm{~m}^{2} / \mathrm{g}$. Total concentration of acid sites according to TPD of ammonia is $532 \mu \mathrm{mol} / \mathrm{g}$ [47]. The influence of the content of active metal and zeolite on the catalytic activity and selectivity of BTX production and the formation of the catalyst was also studied.

The structure and morphology of the catalysts obtained in situ were investigated by transmission electron microscopy (TEM) (JEOL, Tokyo, Japan), FEI Tecnai Osiris TEM at an accelerating voltage of $200 \mathrm{keV}$. For transmission electron microscopy (TEM), a FEI Tecnai Osiris TEM with an accelerating voltage of $200 \mathrm{keV}$ was used.

To measure the $(\mathrm{Ni}) \mathrm{WS}_{2}$ dispersion, the average fraction of $\mathrm{W}$ atoms at the $(\mathrm{Ni}) \mathrm{WS}_{2}$ edge surface was calculated, assuming that the sulfide slabs were perfect hexagons $[47,53]$. The presence of a certain number of nickel atoms is not considered. Dispersion $(D)$ was statistically evaluated by dividing the total number of $\mathrm{W}$ atoms at the edge surface (We), including corner sites $(W c)$, by the total number of $\mathrm{W}$ atoms $\left(W_{\mathrm{T}}\right)$ using the slab sizes measured in the TEM micrographs:

$$
\begin{gathered}
D=\frac{W \mathrm{e}+W \mathrm{c}}{W_{T}} \\
W e=\left(6 \times n_{i}-12\right) \times \bar{N} \\
W c=6 \times \bar{N} \\
W_{T}=\left(3 \times n_{i}^{2}-3 \times n_{i}+1\right)
\end{gathered}
$$

where $n_{i}$ is the number of $\mathrm{W}$ atoms along one side of the $(\mathrm{Ni}) \mathrm{WS}_{2}$ slab, as determined by its average length $\bar{L}$.

$$
\bar{L}=\frac{\sum l_{i}}{n}
$$

where $l_{i}$ is a length of each slab.

$$
n_{i}=\frac{10 \times \frac{\overline{\bar{L}}}{3.2}+1}{2}
$$

and

$$
\bar{N}=\frac{\sum n_{i} N_{i}}{n}
$$

where $\bar{N}$ in the average stacking degree and $n_{i}$ is the number of stacks in $N_{i}$ layers.

The XPS analysis of catalysts was performed by ESCALAB MK2 electronic spectrometer (Vacuum Generators LTD) (Physical Electronics, Chanhassen, MN, USA). The samples were studied without heating and ion-beam treatment. The position of the lines of the elements was normalized to the position of $\mathrm{C} 1 \mathrm{~s}$ carbon line of the hydrocarbon contamination of the surface. The survey spectrum was measured at an analyzer bandwidth of $50 \mathrm{eV}$ and a scanning interval of $0.25 \mathrm{eV}$; the particular spectra of 
the elements were measured at a bandwidth of $20 \mathrm{eV}$ and a scanning interval of $0.2 \mathrm{eV}$. Deconvolution of the spectra was conducted by non-linear least-square method using the Gaussian-Lorentzian function.

The absolute content of the Ni-W-S phase on the catalyst surface $\left(\mathrm{C}_{\mathrm{NiWS}}\right)$ was calculated using the formula:

$$
\mathrm{C}_{\mathrm{NiWS}}=\frac{[\mathrm{NiWS}] * \mathrm{C}_{\mathrm{Ni}}}{100}
$$

where [NiWS] is the relative Ni content in the Ni-W-S phase, $\% ; \mathrm{C}_{\mathrm{Ni}}$ is the content of $\mathrm{Ni}$ atoms on the catalyst surface determined by the XPS method, at. \%.

The absolute content of the $\mathrm{WS}_{2}$ phase on the catalyst surface $\left(\mathrm{C}_{\mathrm{WS} 2}\right)$ was calculated from the formula:

$$
\mathrm{C}_{\mathrm{WS} 2}=\frac{\left[\mathrm{WS}_{2}\right] * \mathrm{C}_{W}}{100}
$$

where $\left[\mathrm{WS}_{2}\right]$ is the relative $\mathrm{W}$ content in the $\mathrm{WS}_{2}$ phase, $\% ; \mathrm{C}_{\mathrm{W}}$ is the content of $\mathrm{W}$ atoms on the catalyst surface determined by the XPS method, at. \%.

The promoter ratio in the active phase slab was determined:

$$
(\mathrm{Ni} / \mathrm{W}) \mathrm{slab}=\frac{\mathrm{C}_{\mathrm{Ni}-\mathrm{W}-\mathrm{S}}}{\mathrm{C}_{W S_{2}}}
$$

\subsection{Catalytic Tests}

A number of experiments were carried out, first at a model mixture, to determine the best conditions for hydrocracking, and then at a fraction of pyrolysis fuel oil (PFO). A $10 \%$ solution of naphthalene in hexadecane was chosen as a model mixture. Hydrocracking was carried out in an autoclave-type batch reactor (Stainless steel high-pressure batch reactor). A sample of the catalyst (precursors $\mathrm{W}(\mathrm{CO})_{6}, \mathrm{Ni}\left(\mathrm{C}_{7} \mathrm{H}_{15} \mathrm{COO}\right)_{2}$ and zeolite $\mathrm{HY}$ ) was placed in it. The absence of the external diffusion limitations was checked in a separate test.

The sulfiding of the catalysts was carried out directly in the reaction medium by adding elemental sulfur in an amount of $2.5 \mathrm{wt}$. \% in terms of raw materials. Then, the autoclave was sealed and filled with hydrogen to a pressure of $5.0 \mathrm{MPa}$, the reaction duration was $5 \mathrm{~h}$. We varied the process temperature $\left(350-400{ }^{\circ} \mathrm{C}\right)$, zeolite cont $(0.5$ and $1 \mathrm{wt} \%)$ and $\mathrm{W}(1-4 \mathrm{wt} \%)$ in the reaction medium, the ratio $\mathrm{Ni} / \mathrm{W}=2: 1$. The tungsten content in the raw material was calculated using the following formula:

$$
W=\frac{\mathrm{m}\left(\mathrm{W}(\mathrm{CO})_{6}\right) \mathrm{M}(\mathrm{W})}{\mathrm{M}\left(\mathrm{W}(\mathrm{CO})_{6}\right) \mathrm{m}(\text { сырья })} \times 10^{6}[\mathrm{ppm}]
$$

where $\mathrm{m}\left(\mathrm{W}(\mathrm{CO})_{6}\right)$ is the mass of tungsten hexacarbonyl dissolved in the hydrocarbon raw material, $\mathrm{g}$; $\mathrm{M}(\mathrm{W})$ is molar mass of tungsten, $183.8 \mathrm{~g} / \mathrm{mol} ; \mathrm{M}\left(\mathrm{W}(\mathrm{CO})_{6}\right)$ is molar mass of tungsten hexacarbonyl, $351.9 \mathrm{~g} / \mathrm{mol}$; $\mathrm{m}$ (raw material) is the mass of hydrocarbon raw material, $\mathrm{g}$.

The start time of the experiment was considered the moment when the required reaction temperature was established. Upon completion of the reaction, the autoclave was cooled to room temperature and depressurized. The catalyst was separated from the products by centrifugation, and the liquid reaction products were analyzed by gas-liquid chromatography method.

\subsection{Products Characterization}

Qualitative analysis of liquid products was carried out using Agilent 6890 gas-liquid chromatograph with Finnigan MAT 95 XL mass spectrometric detector (Thermo Scientific) (Supelco, Bellefonte, PA, USA), Varian VF-5MS capillary column $(30 \mathrm{~m} \times 0.25 \mathrm{~mm} \times 0.25 \mu \mathrm{m})$, with helium as carrier gas. The quantitative and fractional composition of liquid products (gasoline fraction $<180^{\circ} \mathrm{C}$, diesel fraction $180-360^{\circ} \mathrm{C}$, residual fraction $>360^{\circ} \mathrm{C}$ ) was determined by simulated distillation using a Kristallux $4000 \mathrm{M}$ gas-liquid chromatograph with a flame ionization detector, capillary column SPB-1 $(30 \mathrm{~m} \times 0.25 \mathrm{~mm} \times 0.25 \mu \mathrm{m})$ (Meta-Khrom, Yoshkar-Ola, Russia) with helium as carrier gas. 
The naphthalene conversion (conversion, \%) was calculated as the degree of conversion of the initial aromatic compound into hydrocracking products.

\section{Conclusions}

In this paper, hydrocracking of a pyrolysis fuel oil in a slurry reactor on in situ synthesized NiWS-HY catalysts from low-soluble precursors for the selective production of the BTX fraction was studied for the first time. The qualitative and quantitative composition of the hydrocracking products was studied. It was found that the yield of benzene-toluene-xylenes can reach up to $15 \%$ of the total mass of the products. An increase was also noted for the proportion of light products of hydrocracking.

Thus, we can conclude that NiWS-HY catalyst can be considered as a catalyst for the hydrocracking of pyrolysis fuel oil. Moreover, varying the process conditions led to a change in the selectivity for the products of BTX fraction.

The optimal conditions for the process of obtaining BTX fraction from pyrolysis fuel oil were determined. At $380{ }^{\circ} \mathrm{C}$, with $4 \mathrm{wt} \%$ of tungsten, and $1 \mathrm{wt} \%$ and $0.5 \mathrm{wt} \%$ of zeolite, the amount of the product was much greater. The best result was obtained at $380{ }^{\circ} \mathrm{C}$, with $4 \mathrm{wt} \%$ of tungsten, and $1 \mathrm{wt} \%$ of zeolite, where mass of BTX fraction was about 15\%.

The catalyst obtained under these conditions was characterized by XPS method; it was found that with a lower content of zeolite more of the hydrogenating Ni-W-S phase was formed. This is also confirmed by the TEM results.

Author Contributions: Conceptualization, T.K., M.K., V.S., and A.M.; methodology, M.K.; investigation, T.K.; data curation, T.K.; writing-original draft preparation, T.K.; writing-review and editing, A.M. and V.S.; supervision, A.M.; project administration, A.M. All authors have read and agreed to the published version of the manuscript.

Funding: This research received no external funding.

Acknowledgments: This work was carried out within the State Program of TIPS RAS.

Conflicts of Interest: The authors declare no conflict of interest.

\section{Appendix A}

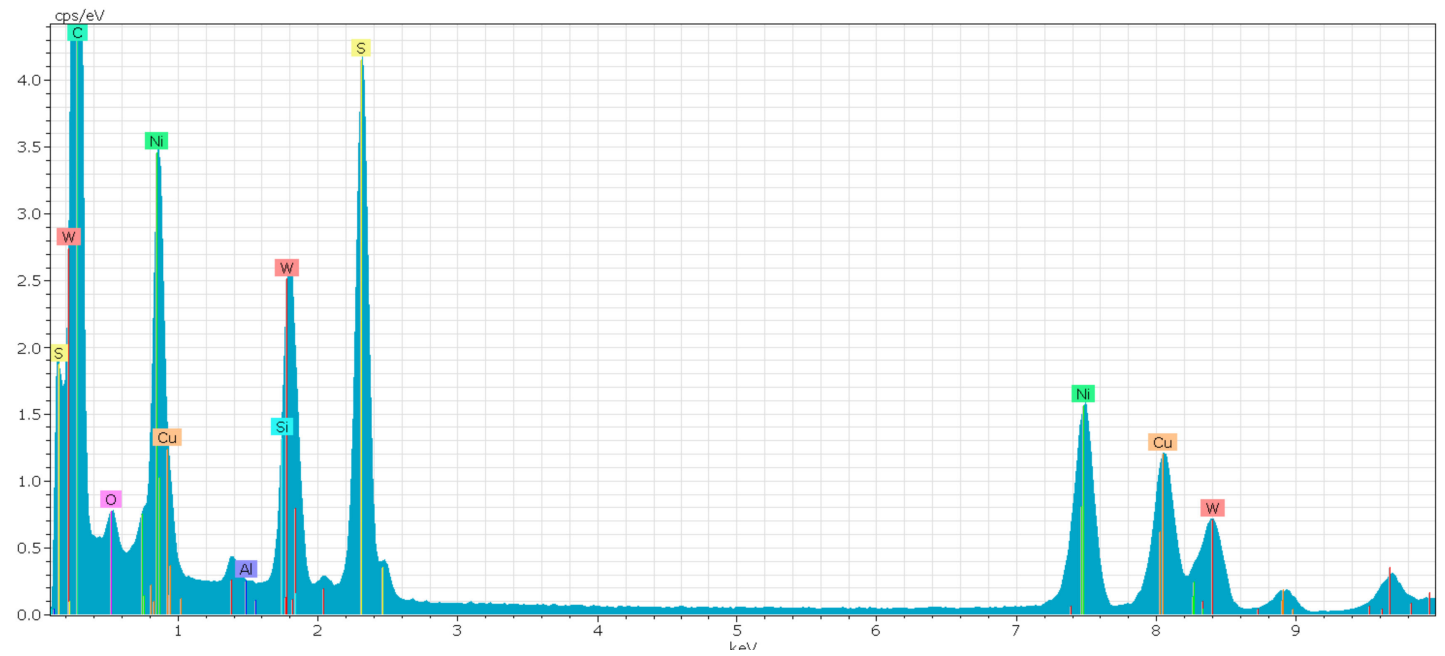

Figure A1. EDX spectrum of catalyst NiWS-HY (0.5\%). 


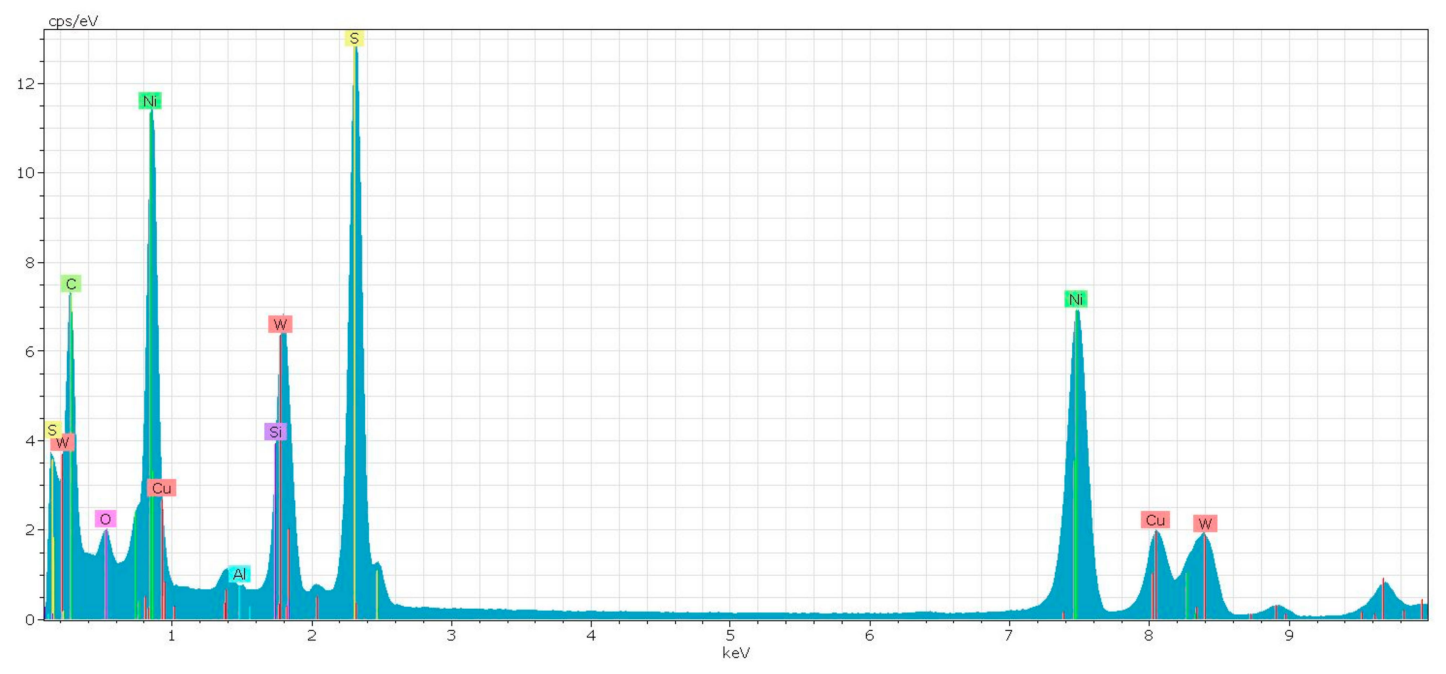

Figure A2. EDX spectrum of catalyst NiWS-HY (1\%).

\section{References}

1. Yan, J.D. Biomass to energy in china: Development status and strategic consideration. Chem. Ind. For. Prod. 2014, 34, 151-158.

2. Cho, M.H.; Jung, S.H.; Kim, J.S. Pyrolysis of mixed plastic wastes for the recovery of benzene, toluene, and xylene (BTX) aromatics in a fluidized bed and chlorine removal by applying various additives. Energy Fuels 2010, 24, 1389-1395. [CrossRef]

3. Xu, X.W.; Jiang, E.C. "BTX" from guaiacol HDO under atmospheric pressure: The effect of support and the carbon deposition. Energy Fuels 2017, 31, 2855-2864. [CrossRef]

4. Xu, N.; Pan, D.; Wu, Y.; Xu, S.; Gao, L.; Zhang, J.; Xiao, G. Preparation of nano-sized HZSM-5 zeolite with sodium alginate for glycerol aromatization. React. Kinet. Mech. Catal. 2019, 127, 449-467. [CrossRef]

5. Song, W.; Zhou, S.; Hu, S.; Lai, W.; Lian, Y.; Wang, J.; Jiang, X. Surface engineering of CoMoS nano-sulfide for hydrodeoxygenation of lignin-derived phenols to arenes. ACS Catal. 2019, 9, 259-268. [CrossRef]

6. Jung, S.H.; Cho, M.H.; Kang, B.S.; Kim, J.S. Pyrolysis of a fraction of waste polypropylene and polyethylene for the recovery of BTX aromatics using a fluidized bed reactor. Fuel Process. Technol. 2010, 91, $277-284$. [CrossRef]

7. Xu, X.W.; Jiang, E.C.; Li, Z.Y.; Sun, Y. BTX from anisole by hydrodeoxygenation and transalkylation at ambient pressure with zeolite catalysts. Fuel 2018, 221, 440-446. [CrossRef]

8. Tamiyakul, S.; Ubolcharoen, W.; Tungasmita, D.N.; Jongpatiwut, S. Conversion of glycerol to aromatic hydrocarbons over Zn-promoted HZSM-5 catalysts. Catal. Today 2015, 256, 325-335. [CrossRef]

9. Laredo, G.C.; Pérez-Romo, P.; Escobar, J.; Garcia-Gutierrez, J.L.; Vega-Merino, P.M. Light cycle oil upgrading to benzene, toluene, and xylenes by hydrocracking: Studies using model mixtures. Ind. Eng. Chem. Res. 2017, 56, 10939-10948. [CrossRef]

10. Polliotto, V.; Livraghi, S.; Agnoli, S.; Granozzi, G.; Giamello, E. Reversible adsorption of oxygen as superoxide ion on cerium doped zirconium titanate. Appl. Catal. A Gen. 2019, 580,140-148. [CrossRef]

11. Choi, Y.; Lee, J.; Shin, J.; Lee, S.; Kim, D.; Lee, J.K. Selective hydroconversion of naphthalenes into light alkyl-aromatic hydrocarbons. Appl. Catal. A Gen. 2015, 492, 140-150. [CrossRef]

12. Kim, Y.-S.; Cho, K.-S.; Lee, Y.-K. Structure and activity of $\mathrm{Ni}_{2} \mathrm{P} /$ desilicated zeolite $\beta$ catalysts for hydrocracking of pyrolysis fuel oil into benzene, toluene, and xylene. Catalyst 2020, 10, 47. [CrossRef]

13. Upare, D.P.; Park, S.; Kim, M.S.; Jeon, Y.-P.; Kim, J.; Lee, D.; Lee, C.W. Selective hydrocracking of pyrolysis fuel oil into benzene, toluene and xylene over CoMo/beta zeolite catalyst. J. Ind. Eng. Chem. 2017, 46, 356-363. [CrossRef]

14. Sato, K.; Iwata, Y.; Miki, Y.; Shimad, H. Hydrocracking of TEtralin over NiW/USY zeolite catalysts: For the improvement of heavy-oil upgrading catalysts. J. Catal. 1999, 186, 45-56. [CrossRef] 
15. Ishihara, A.; Itoh, T.; Nasu, H.; Hashimoto, T.; Doi, T. Hydrocracking of 1-methylnaphthalene/ decahydronaphthalene mixture catalyzed by zeolite-alumina composite supported NiMo catalysts. Fuel Process. Technol. 2013, 116, 222-227. [CrossRef]

16. Park, J.I.; Lee, J.K.; Miyawaki, J.; Kim, Y.K.; Yoon, S.H.; Mochida, I. Hydro-conversion of 1-methyl naphthalene into (alkyl)benzenes over alumina-coated USY zeolite-supported NiMoS catalysts. Fuel 2011, 90, 182-189. [CrossRef]

17. Ali, M.A.; Tatsumi, T.; Masuda, T. Development of heavy oil hydrocracking catalysts using amorphous silica-alumina and zeolites as catalyst supports. Appl. Cataly. A Gen. 2002, 233, 77-90. [CrossRef]

18. Silva-Rodrigo, R.; Calderón-Salas, C.; Melo-Banda, J.A.; Domínguez, J.M.; Vázquez-Rodríguez, A. Synthesis, characterization and comparison of catalytic properties of NiMo- and NiW/Ti-MCM-41 catalysts for HDS of thiophene and HVGO. Catal. Today 2004, 98, 123-129. [CrossRef]

19. Leyva, C.; Rana, M.S.; Trejo, F.; Ancheyta, J. On the use of acid-base-supported catalysts for hydroprocessing of heavy petroleum. Ind. Eng. Chem. Res. 2007, 46, 7448-7466. [CrossRef]

20. Leyva, C.; Rana, M.S.; Trejo, F.; Ancheyta, J. NiMo supported acidic catalysts for heavy oil hydroprocessing. Catal. Today 2009, 141, 168-175. [CrossRef]

21. Tiwari, R.; Rana, B.S.; Kumar, R.; Verma, D.; Kumar, R.; Joshi, R.K.; Garg, M.O.; Sinha, A.K. Hydrotreating and hydrocracking catalysts for processing of waste soya-oil and refinery-oil mixtures. Catal. Commun. 2011, 12, 559-562. [CrossRef]

22. Looi, P.Y.; Mohamed, A.R.; Tye, C.T. Hydrocracking of residual oil using molybdenum supported over mesoporous alumina as a catalyst. Chem. Eng. J. 2012, 181, 717-724. [CrossRef]

23. Nishijima, A.; Shimada, H.; Sato, T.; Yoshimur, Y.; Hiraishi, J. Support effects on hydrocarcking and hydrogenation activities of molybdenum catlysts used for upgrading coal-derived liquids. Polyhedron 1986, 5, 243-247. [CrossRef]

24. Shimada, H. Morphology, dispersion and catalytic functions of supported molybdenum sulfide catalysts for hydrotreating petroleum fractions. J. Jpn. Pet. Inst. 2016, 59, 46-58. [CrossRef]

25. Castillo-Villalón, P.; Ramírez, J.; Cuevas, R.; Vázquez, P.; Castañeda, R. Influence of the support on the catalytic performance of $\mathrm{Mo}, \mathrm{CoMo}$, and NiMo catalysts supported on $\mathrm{Al}_{2} \mathrm{O}_{3}$ and $\mathrm{TiO}_{2}$ during the HDS of thiophene, dibenzothiophene, or 4,6-dimethyldibenzothiophene. Catal. Today 2016, 259, 140-149. [CrossRef]

26. Laredo, G.C.; Pérez-Romo, P.; Vega-Merino, P.M.; Arzate-Barbosa, E.; García-López, A.; Agueda-Rangel, R.; Martínez-Moreno, V.H. Effect of the catalytic system and operating conditions on BTX formation using tetralin as a model molecule. Appl. Petrochem. Res. 2019, 9, 185-198. [CrossRef]

27. Upare, D.P.; Park, S.; Kim, M.S.; Kim, J.; Lee, D.; Lee, J.; Lee, C.W. Cobalt promoted Mo/beta zeolite for selective hydrocracking of tetralin and pyrolysis fuel oil into monocyclic aromatic hydrocarbons. J. Ind. Eng. Chem. 2016, 35, 99-107. [CrossRef]

28. Yi, Y.; Jin, X.; Wang, L.; Zhang, Q.; Xiong, G.; Liang, C. Preparation of unsupported Ni-Mo-S catalysts for hydrodesulfurization of dibenzothiophene by thermal decomposition of tetramethylammonium thiomolybdates. Catal. Today 2011, 175, 460. [CrossRef]

29. Olivas, A.; Zepeda, T.A.; Villalpando, I.; Fuentes, S. Performance of unsupported Ni(Co,Fe)/MoS2 catalysts in hydrotreating reactions. Catal. Commun. 2008, 9, 1317-1328. [CrossRef]

30. Beller, M.; Renken, A.; van Santen, R.A. Catalysis: From Principles to Applications; Wiley: Hoboken, NJ, USA, 2012.

31. Furimsky, E.; Massoth, F.E. Deactivation of hydroprocessing catalysts. Catal. Today 1999, 52, $381-495$. [CrossRef]

32. Hagenbach, G.; Courty, P.; Delmon, B. Physicochemical investigations and catalytic activity measurements on crystallized molydbenum sulfide-cobalt sulfide mixed catalysts. Catalyst 1973, 31, 264-273. [CrossRef]

33. Tops $\oslash$ e, H.; Clausen, B.S. Importance of Co-Mo-S type structures in hydrodesulfurization. Catal. Rev. 1984, 26, 395-420. [CrossRef]

34. Hur, Y.G.; Kim, M.-S.; Lee, D.-W.; Kim, S.; Eom, H.-J.; Jeong, G.; Lee, K.-Y. Hydrocracking of vacuum residue into lighter fuel oils using nanosheet-structured WS 2 catalyst. Fuel 2014, 137, 237-244. [CrossRef]

35. Bellussi, G.; Rispoli, G.; Landoni, A.; Millini, R.; Molinari, D.; Montanari, E.; Moscotti, D.; Pollesel, P. Hydroconversion of heavy residues in slurry reactors: Developments and perspectives. J. Catal. 2013, 308, 189-200. [CrossRef] 
36. Knyazeva, M.I.; Panyukova, D.I.; Kuchinskaya, T.S.; Kulikov, A.B.; Maximov, A.L. Effect of composition of cobalt-molybdenum-containing sulfonium thiosalts on the hydrogenation activity of nanosized catalysts in situ synthesized on their basis. Pet. Chem. 2019, 59, 1285-1292. [CrossRef]

37. Kennepohl, D.; Sanford, E. Conversion of athabasca bitumen with dispersed and supported mo-based catalysts as a function of dispersed catalyst concentration. Energy Fuels 1996, 10, 229-234. [CrossRef]

38. Alonso, G.; Chianelli, R.R. WS2 catalysts from tetraalkyl thiotungstate precursors and their concurrent in situ activation during HDS of DBT. J. Catal. 2004, 221, 657-661. [CrossRef]

39. Jeong, H.-R.; Lee, Y.K. Comparison of unsupported WS2 and MoS2 catalysts for slurry phase hydrocracking of vacuum residue. Appl. Catal. A Gen. 2019, 572, 90-96. [CrossRef]

40. Sizova, I.A.; Panyukova, D.I.; Maksimov, A.L. Hydrotreating of high-aromatic waste of coke and by-product processes in the presence of in situ synthesized sulfide nanocatalysts. Pet. Chem. 2017, 57, 1304-1309. [CrossRef]

41. Onishchenko, M.I.; Kulikov, A.B.; Maksimov, A.L. Application of zeolite Y-based Ni-W supported and in situ prepared catalysts in the process of vacuum gas oil hydrocracking. Pet. Chem. 2017, 57, 1287-1294. [CrossRef]

42. Hur, Y.G.; Lee, D.-W.; Lee, K.-Y. Hydrocracking of vacuum residue using NiWS(x) dispersed catalysts. Fuel 2016, 185, 794-803. [CrossRef]

43. Jeon, S.G.; Na, J.-G.; Ko, C.H.; Lee, K.B.; Rho, N.S.; Park, S.B. A new approach for preparation of oil-soluble bimetallic dispersed catalyst from layered ammonium nickel molybdate. Mater. Sci. Eng. B. 2011, 176, 606-610. [CrossRef]

44. Ben Tayeb, K.; Lamonier, C.; Lancelot, C.; Fournier, M.; Payen, E.; Bonduelle, A.; Bertoncini, F. Study of the active phase of $\mathrm{NiW}$ hydrocracking sulfided catalysts obtained from an innovative heteropolyanion based preparation. Catal. Today 2010, 150, 207-212. [CrossRef]

45. McDonald, W.; Friesen, G.D.; Rosenhein, L.D.; Newton, W.E. Syntheses and characterization of ammonium and tetraalkylammonium thiomolybdates and thiotungstates. Inorg. Chim. Acta 1983, 72, 205-210. [CrossRef]

46. Furimsky, E. Catalyst for Upgrading Heavy Petroleum Feed; Elsevier: Amsterdam, The Netherlands, $2007 ;$ p. 404.

47. Kniazeva, M.; Maximov, A. Effect of additives on the activity of Nickel-Tungsten sulfide hydroconversion catalysts prepared in situ from oil-soluble precursors. Catalysts 2018, 8, 644. [CrossRef]

48. Zhu, L.; Sun, H.; Fu, H.; Zheng, J.; Zhang, N.; Li, Y.; Chen, B.H. Effect of ruthenium nickelbimetallic composition on the catalytic performance for benzene hydrogenation tocyclohexane. Appl. Catal. A Gen. 2015, 49, 124-132. [CrossRef]

49. Hensen, E.J.M.; van der Meer, Y.; van Veen, J.A.R.; Niemantsverdriet, J.W. Insight into the formation of theactive phases in supported NiW hydrotreating catalysts. Appl. Catal. A Gen. 2007, 322, 16-32. [CrossRef]

50. Díaz de León, J.N.; Antunes-García, J.; Alonso-Nuñez, G.; Zepeda, T.A.; Galvan, D.H.; de los Reyes, J.A.; Fuentes, S. Support effects of NiW hydrodesulfurization catalysts from experiments and DFT calculations. Appl. Catal. B Environ. 2018, 238, 480-490. [CrossRef]

51. Eijsbouts, S.; Li, X.; Bergwerff, J.; Louwen, J.; Woning, L.; Loos, J. Nickel sulfide crystals in Ni-Mo and Ni-W catalysts: Eye-catching inactive feature or an active phase in its own right? Catal. Today 2017, 292, 38-50. [CrossRef]

52. Voorhoeve, $R$. The mechanism of the hydrogenation of cyclohexene and benzene on nickel-tungsten sulfide catalysts. J. Catal. 1971, 23, 243-252. [CrossRef]

53. Kasztelan, S.; Toulhoat, H.; Grimblot, J.; Bonnelle, J.P. A geometrical model of the active phase of hydrotreating catalysts. Appl. Catal. 1984, 13, 127-159. [CrossRef]

(C) 2020 by the authors. Licensee MDPI, Basel, Switzerland. This article is an open access article distributed under the terms and conditions of the Creative Commons Attribution (CC BY) license (http://creativecommons.org/licenses/by/4.0/). 